\title{
Design of Fuzzy Fractional PD + I Controllers Tuned by a Genetic Algorithm
}

\author{
Isabel S. Jesus and Ramiro S. Barbosa \\ Department of Electrical Engineering, Institute of Engineering/Polytechnic of Porto (ISEP/IPP), GECAD, \\ Knowledge Engineering and Decision Support Research Center, 4200-072 Porto, Portugal
}

Correspondence should be addressed to Isabel S. Jesus; isj@isep.ipp.pt

Received 28 October 2013; Revised 25 March 2014; Accepted 8 April 2014; Published 7 May 2014

Academic Editor: Jyh-Hong Chou

Copyright (C) 2014 I. S. Jesus and R. S. Barbosa. This is an open access article distributed under the Creative Commons Attribution License, which permits unrestricted use, distribution, and reproduction in any medium, provided the original work is properly cited.

\begin{abstract}
The fractional-order concepts are a useful tool to describe several physical phenomena, and nowadays they are widely used in the field of automatic control. A genetic algorithm (GA) is a search process for finding approximate solutions in optimization problems. The GA provides further flexibility and robustness that are unique for signal process. In this paper we consider the development of an optimal fuzzy fractional PD + I controller in which the parameters are tuned by a GA. The performance of the proposed fuzzy fractional control is illustrated through some application examples.
\end{abstract}

\section{Introduction}

Fractional calculus (FC) is a generalization of integration and differentiation to a noninteger order $\alpha \in C$, with the fundamental operator being ${ }_{a} D_{t}^{\alpha}$, where $a$ and $t$ are the limits of the operation $[1,2]$. The FC concepts constitute a useful tool to describe several physical phenomena, such as heat, flow, electricity, magnetism, mechanics, or fluid dynamics. Presently, the FC theory is applied in almost all areas of science and engineering, with its ability being recognized in bettering the modelling and control of many dynamical systems. In fact, during the last years FC has been used increasingly to model the constitutive behavior of materials and physical systems exhibiting hereditary and memory properties. This is the main advantage of fractionalorder derivatives in comparison with classical integer-order models, where these effects are simply neglected.

In this paper we investigate several control strategies/structures based on fuzzy fractional-order algorithms. The fractional-order PID controller $\left(\mathrm{PI}^{\alpha} \mathrm{D}^{\beta}\right.$ controller) involves an integrator of order $\alpha \in \mathfrak{R}^{+}$and a differentiator of order $\beta \in \mathfrak{R}^{+}$. It was demonstrated the good performance of this type of controller in comparison with the conventional PID algorithms. Recently, there have been a lot of researches in the application of fuzzy PID control [3-9]. The fuzzy method offers a systematic procedure to design controllers for many kinds of systems that often leads to a better performance than that of the conventional PID controller. It is a methodology of intelligent control that mimics human thinking and reacting by using a multivalent fuzzy logic and elements of artificial intelligence.

It was proved that the use of the fuzzy fractional controllers improved the results for many kinds of systems, since it gives additional flexibility to the design. In this line of thought many applications of this type of controllers were developed in the last few years. For example, in $[3,4]$, the authors proved the effectiveness of fuzzy fractional PD and PID controllers in terms of their digital implementation and robustness. In [10], an intelligent robust fractional surface sliding mode control for a nonlinear system is studied. In [6], a fractional-order fuzzy PID controller was proposed and compared to classical PID, fuzzy PID, and even $\mathrm{PI}^{\lambda} \mathrm{D}^{\mu}$ controllers. Many other applications can be found in [11-16].

A genetic algorithm (GA) is a search technique based on the natural selection process. The GA is a particular class of evolutionary algorithms that use techniques inspired by evolutionary biology such as inheritance, mutation, natural selection, and crossover, established by Darwin's theory of evolution [17-19]. The GA is used in the field of robotics, strategy planning, nonlinear dynamical systems, data analysis, art, evolving pictures, music, and many others in the real world applications [17-20]. The GA provides a unique flexibility 
and robustness for process optimization. Due to this reason, during the last years many control applications used the GA in order to find better results. For example, in [6], the authors optimized their system with GA while minimizing several integral error indices along with the control signal as the objective function. Hu et al. [21] developed a methodology for the systematic design of fuzzy PID controllers based on genetic optimization, where they proved that the proposed system always provides the best control performance. In [22], the GA was used for tuning the PI controller for load frequency control. Herrera and Lozano showed in [23] the benefits derived from the synergy between evolutionary algorithms and fuzzy logic systems.

Bearing these ideas in mind, the paper is organized as follows. Section 2 gives the fundamentals of fractional-order control systems. Section 3 presents the control and optimization strategies. Section 4 gives some simulations results assessing the effectiveness of the proposed methodology. Finally, Section 5 draws the main conclusions.

\section{Fractional-Order Control Systems}

Fractional-order control systems are characterized by differential equations that have, in the dynamical system and/or in the control algorithm, an integral and/or a derivative of fractional order $[24,25]$. Due to the fact that these operators are defined by irrational continuous transfer functions, in the Laplace domain, or infinite dimensional discrete transfer functions, in the $Z$ domain, we often encounter evaluation problems in the simulations. Therefore, when analyzing fractional-order systems, we usually adopt continuous or discrete integer-order approximations of fractional-order operators [26-28]. The following two subsections provide a background for the remaining of the paper by giving the fundamental aspects of the FC and the discrete integer-order approximations of fractional-order operators used in this study.

2.1. Fundamentals of Fractional Calculus. The mathematical definition of a fractional-order derivative and integral (socalled differintegral) has been the subject of several different approaches $[1,2]$. One commonly used definition for the fractional-order derivative is given by the Riemann-Liouville definition $(\alpha>0)$ :

$$
\begin{array}{r}
{ }_{a} D_{t}^{\alpha} f(t)=\frac{1}{\Gamma(n-\alpha)} \frac{d^{n}}{d t^{n}} \int_{a}^{t} \frac{f(\tau)}{(t-\tau)^{\alpha-n+1}} d \tau, \\
n-1<\alpha<n,
\end{array}
$$

where $n$ is integer, $f(t)$ is the applied function, and $\Gamma(x)$ is the Gamma function of $x$. Another widely used definition is given by the Grünwald-Letnikov approach $(\alpha \in \Re)$ :

$$
\begin{gathered}
{ }_{a} D_{t}^{\alpha} f(t)=\lim _{h \rightarrow 0} \frac{1}{h^{\alpha}} \sum_{k=0}^{[(t-a) / h]}(-1)^{k}\left(\begin{array}{l}
\alpha \\
k
\end{array}\right) f(t-k h), \\
\left(\begin{array}{l}
\alpha \\
k
\end{array}\right)=\frac{\Gamma(\alpha+1)}{\Gamma(k+1) \Gamma(\alpha-k+1)}
\end{gathered}
$$

where $h$ is the time increment and $[x]$ means the integer part of $x$.

Another definition is given by the Caputo approach:

$$
{ }_{a}^{C} D_{t}^{\alpha} f(t)=\frac{1}{\Gamma(n-\alpha)} \int_{a}^{t} \frac{f^{n}(\tau)}{(t-\tau)^{\alpha+1-n}} d \tau, \quad n-1<\alpha<n .
$$

The "memory" effect of these operators is demonstrated by (1)-(3), where the convolution integral in (1) and (3) and the infinite series in $(2 \mathrm{a})$ and $(2 \mathrm{~b})$ reveal the unlimited memory of these operators, ideal for modelling hereditary and memory properties in physical systems and materials.

An alternative definition to (1)-(3), which reveals useful for the analysis of fractional-order control systems, is given by the Laplace transform method. Considering vanishing initial conditions, the fractional differintegration is defined in the Laplace domain, $F(s)=L\{f(t)\}$, as

$$
L\left\{{ }_{a} D_{t}^{\alpha} f(t)\right\}=s^{\alpha} F(s), \quad \alpha \in \Re .
$$

The fractional operator can be more easily interpreted in the frequency domain. In fact, the open-loop Bode diagrams of amplitude and phase of $s^{\alpha}$ have correspondingly a slope of $20 \alpha \mathrm{dB} / \mathrm{dec}$ and a constant phase positioned at $\alpha \pi / 2$ rad over the entire frequency domain.

2.2. Approximations of Fractional-Order Operators. In this study we adopt discrete integer-order approximations to the fundamental element $s^{\alpha}(\alpha \in \Re)$ of a fractional-order control (FOC) strategy. The usual approach for obtaining discrete equivalents of continuous operators of type $s^{\alpha}$ adopts the Euler, Tustin, and Al-Alaoui generating functions [26, 29, 30].

It is well known that rational-type approximations frequently converge faster than polynomial-type approximations and have a wider domain of convergence in the complex domain [29]. Thus, using the Euler operator $w\left(z^{-1}\right)=$ $\left(1-z^{-1}\right) / T_{c}$ and performing a power series expansion of $\left[w\left(z^{-1}\right)\right]^{\alpha}=\left[\left(1-z^{-1}\right) / T_{c}\right]^{\alpha}$ give the discretization formula corresponding to the Grünwald-Letnikov Definition (2a) and (2b):

$$
\begin{aligned}
D^{\alpha}\left(z^{-1}\right) & =\left(\frac{1-z^{-1}}{T_{c}}\right)^{\alpha}=\sum_{k=0}^{\infty}\left(\frac{1}{T_{c}}\right)^{\alpha}(-1)^{k}\left(\begin{array}{l}
\alpha \\
k
\end{array}\right) z^{-k} \\
& =\sum_{k=0}^{\infty} h^{\alpha}(k) z^{-k},
\end{aligned}
$$

where $T_{c}$ is the sampling period and $h^{\alpha}(k)$ is the impulse response sequence.

A rational fraction-type approximation can be obtained through a Padé approximation to the impulse response sequence $h^{\alpha}(k)$, yielding the discrete transfer function:

$$
H\left(z^{-1}\right)=\frac{b_{0}+b_{1} z^{-1}+\cdots+b_{m} z^{-m}}{1+a_{1} z^{-1}+\cdots+a_{n} z^{-n}}=\sum_{k=0}^{\infty} h(k) z^{-k},
$$

where $m \leq n$ and the coefficients $a_{k}$ and $b_{k}$ are determined by fitting the first $m+n+1$ values of $h^{\alpha}(k)$ into the impulse 


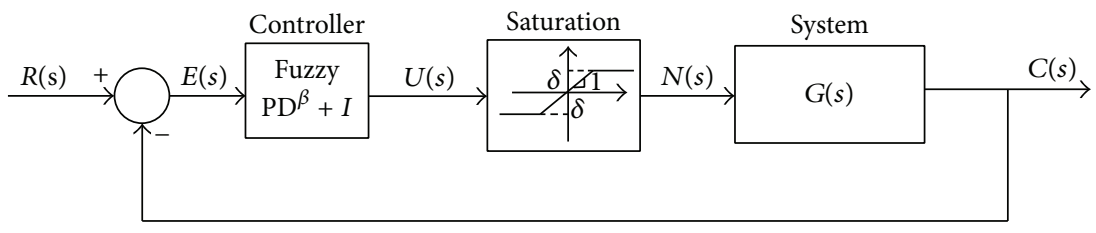

FIGURE 1: Block diagram of the fuzzy control system.

response $h(k)$ of the desired approximation $H\left(z^{-1}\right)$. Thus, we obtain an approximation that matches the desired impulse response $h^{\alpha}(k)$ for the first $m+n+1$ values of $k$ [26]. Note that the above Padé approximation is obtained by considering the Euler operator but the determination process will be exactly the same for other types of discretization schemes.

\section{Control and Optimization Strategies}

3.1. Fractional PID Control. The generalized PID controller, $G_{c}(s)$, has a transfer function of the form [28]

$$
G_{c}(s)=\frac{U(s)}{E(s)}=K_{p}+\frac{K_{i}}{s^{\alpha}}+K_{d} s^{\beta}, \quad \alpha, \beta>0,
$$

where $\alpha$ and $\beta$ are the orders of the fractional integrator and differentiator, respectively. The parameters $K_{p}, K_{i}$, and $K_{d}$ are correspondingly the proportional, integral, and derivative gains of the controller. Clearly, taking $(\alpha, \beta)=$ $\{(1,1),(1,0),(0,1),(0,0)\}$ we get the classical $\{\mathrm{PID}, \mathrm{PI}, \mathrm{PD}, \mathrm{P}\}$ controllers, respectively $[24,31,32]$. Other PID controllers are possible, namely, $\mathrm{PD}^{\beta}$ controller, $\mathrm{PI}^{\alpha}$ controller, $\mathrm{PID}^{\beta}$ controller, and so on. The fractional-order controller is more flexible and gives the possibility of adjusting more carefully the closed-loop system characteristics $[2,33]$.

In the time domain the $\mathrm{PI}^{\alpha} \mathrm{D}^{\beta}$ is represented by

$$
u(t)=K_{p} e(t)+K_{i 0} D_{t}^{-\alpha} e(t)+K_{d{ }_{0}} D_{t}^{\beta} e(t) .
$$

The fractional-order differential operators in (8) are implemented using the approximations (5) and (6), yielding the discrete transfer function:

$$
\begin{aligned}
G_{c}(z) & =\frac{U(z)}{E(z)} \\
& =K_{p}+K_{i} H_{i}\left(z^{-1}\right)+K_{d} H_{d}\left(z^{-1}\right),
\end{aligned}
$$

where $H_{i}\left(z^{-1}\right)$ and $H_{d}\left(z^{-1}\right)$ are the fraction-type approximations to fractional-order integral and derivative, respectively.

3.2. Fuzzy Fractional PD + I Control. Fuzzy control emerged on the foundations of Zadeh's fuzzy set theory [3, 4, 9]. This kind of control is based on the ability of a human being to find solutions for particular problematic situations. It is well known from our experience that humans have the ability to simultaneously process a large amount of information and make effective decisions, although neither input information nor consequent actions is precisely defined. Through multivalent fuzzy logic, linguistic expressions in antecedent and consequent parts of IF-THEN rules describing the operator's actions can be efficaciously converted into a fully structured control algorithm.

The fuzzy logic controllers are not dependent on accurate mathematical models, which are one of the most important advantages in its use, particularly in applications where systems are difficult to model or contain significant nonlinearities.

In the system of Figure 1, we apply a fuzzy logic control (FLC) for the $\mathrm{PD}^{\beta}$ actions and the integral of the error is added to the output in order to find a fuzzy $\mathrm{PD}^{\beta}+$ I controller $[3,34]$. This kind of configuration eliminates the steady state error due to the integer integrative action. The block diagram of Figure 2 illustrates the configuration of the proposed fuzzy controller.

In this controller, the control actions are the error $e$, the fractional derivative of $e$, and the integral of $e$. The $U$ represents the controller output. Also, the controller has four gains to be tuned, $K_{e}, K_{\mathrm{ie}}, K_{\mathrm{ce}}$ corresponding to the inputs and $K_{u}$ to the output.

The control action $U$ is generally a nonlinear function of error $E$, fractional change of error $\mathrm{CE}$, and integral of error IE:

$$
\begin{aligned}
U(k) & =[f(E, \mathrm{CE})+\mathrm{IE}] K_{u} \\
& =\left[f\left(K_{e} e(k), K_{\mathrm{ce}} D^{\beta} e(k)\right)+K_{\mathrm{ie}} I e(k)\right] K_{u},
\end{aligned}
$$

where $D^{\beta}$ is the discrete fractional derivative implemented as rational fraction approximation (6) using the Euler scheme (5); the integral of error is calculated by rectangular integration:

$$
I\left(z^{-1}\right)=\frac{T_{c}}{1-z^{-1}} .
$$

In fact, we can adopt an integral action of fractional order, $\mathrm{I}^{\alpha}$, yielding a fuzzy fractional $\mathrm{PD}^{\beta}+\mathrm{I}^{\alpha}$ controller [3]. However, in this work we consider only values of $\alpha=1$.

To further illustrate the performance of the fuzzy $\mathrm{PD}^{\beta}+\mathrm{I}$ a saturation nonlinearity is included in the closed-loop system of Figure 1 and inserted in series with the output of the fuzzy controller. The saturation element is defined as

$$
n(u)= \begin{cases}u, & |u|<\delta, \\ \delta \operatorname{sign}(u), & |u| \geq \delta,\end{cases}
$$

where $u$ and $n$ are, respectively, the input and the output of the saturation block and $\operatorname{sign}(u)$ is the signum function.

Here we give an emphasis of the proposed FLC presented in Figure 2. The basic structure for FLC is illustrated in Figure 3 [35]. 


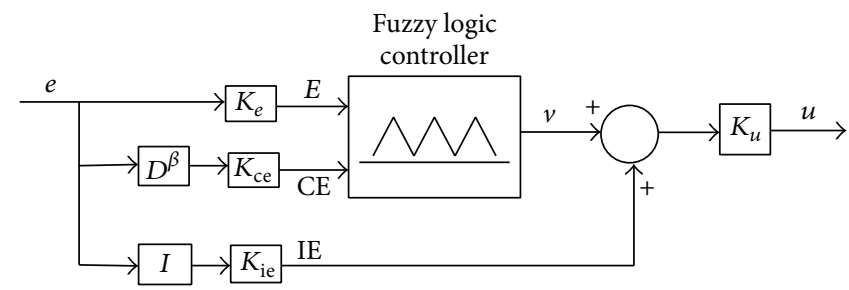

FIGURE 2: Fuzzy PD ${ }^{\beta}+$ I controller.

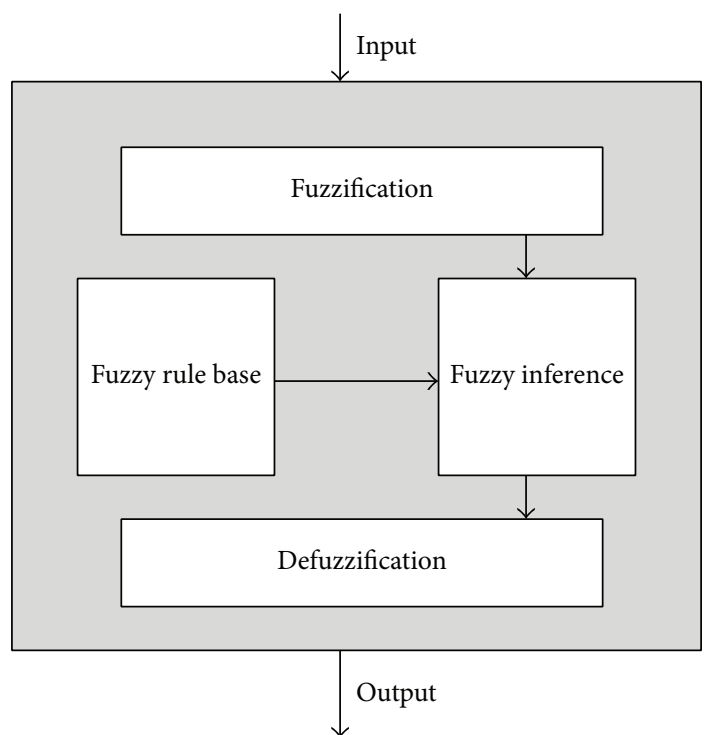

FIGURE 3: Structure for fuzzy logic controller.

TABLE 1: Fuzzy control rules.

\begin{tabular}{lccccccc}
\hline CE & & & \multicolumn{2}{c}{} \\
& NL & NM & NS & ZR & PS & PM & PL \\
\hline NL & NL & NL & NL & NL & NM & NS & ZR \\
NM & NL & NL & NL & NM & NS & ZR & PS \\
NS & NL & NL & NM & NS & ZR & PS & PM \\
ZR & NL & NM & NS & ZR & PS & PM & PL \\
PS & NM & NS & ZR & PS & PM & PL & PL \\
PM & NS & ZR & PS & PM & PL & PL & PL \\
PL & ZR & PS & PM & PL & PL & PL & PL \\
\hline
\end{tabular}

The fuzzy rule base, which reflects the collected knowledge about how a particular control problem must be treated, is one of the main components of a fuzzy controller. The other parts of the controller perform make up the tasks necessary for the controller to be efficient.

For the fuzzy $\mathrm{PD}^{\beta}+$ I controller illustrated in Figure 2, the rule base can be constructed in the following form (see Table 1):

\section{if $E$ is $\mathrm{NM}$ and CE is $\mathrm{NS}$, then $v$ is $\mathrm{NL}$,}

where NL, NM, NS, ZR, PS, PM, and PL are linguistic values representing "negative large," "negative medium," "negative

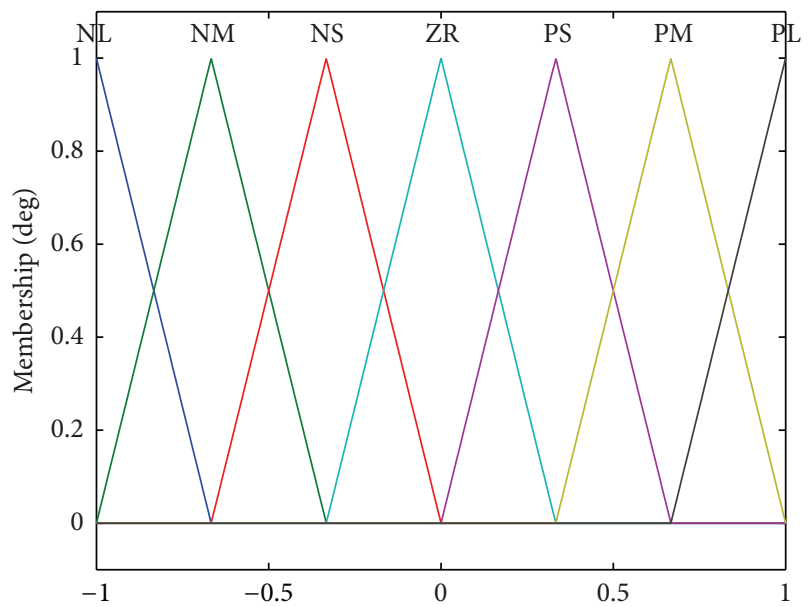

FIgUre 4: Membership functions for $E, \mathrm{CE}$, and $v$.

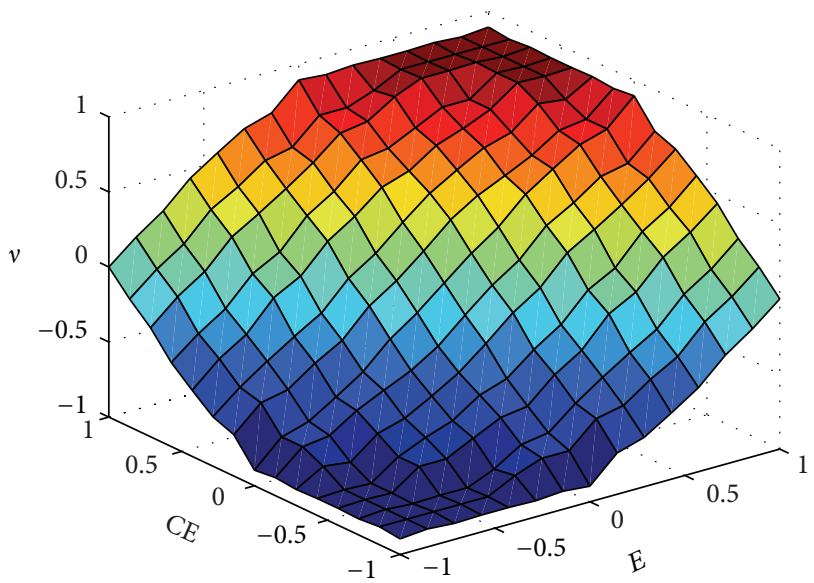

FIgURE 5: Control surface.

small," "zero," "positive small," "positive medium," and "positive large," respectively. $E$ is the error, $\mathrm{CE}$ is the fractional derivative of error, and $v$ is the output of the fuzzy $\mathrm{PD}^{\beta}$ controller. The membership functions for the premises and consequents of the rules are shown in Figure 4.

With two inputs and one output the input-output mapping of the fuzzy logic controller is described by a nonlinear surface, as presented in Figure 5.

The fuzzy controller will be adjusted by changing the parameter values of $K_{e}, K_{\mathrm{ce}}, K_{\mathrm{ie}}$, and $K_{u}$. The fuzzy inference mechanism operates by using the product to combine the 
conjunctions in the premise of the rules and in the representation of the fuzzy implication. For the defuzzification process we use the centroid method.

3.3. Genetic Optimization. The evolutionary computing was introduced in the 60 s by I. Rechenberg, and the GA was invented by John Holland who published a book in 1975 about this subject.

These algorithms begin with a set of solutions, represented by chromosomes, called population $(P)$. Initially, a population is generated randomly. Solutions from one population are taken (parents) and used to form a new $P$. This is motivated by the hope that the new $P$ will be better than the old one. Individuals are then selected to form new solutions according to their fitness; therefore, the more suitable they are the more chances they have to reproduce. This is repeated until some condition is satisfied. Figure 6 presents the block diagram representative of the methodology used in the GA.

In these algorithms the crossover $(C)$ and the mutation $(M)$ operators are the most important parts. The $C$ is a recombination operator that combines subparts of two parent chromosomes to produce offspring that contain some parts of both parents genetic material. The simplest way to do it is to choose some random $C$ point, copy everything before this point from the first parent, and then to copy everything after the $C$ point from the other parent. There are other ways to make $C$; namely, we can choose more $C$ points. The most used way of encoding is a binary string; however, there are many other ways of encoding, such as to encode directly through real numbers.

The selection of a better encoding technique depends on the problem we have to solve. The $M$ operation randomly changes the offspring resulting from $C$. This procedure intended to prevent falling of all solutions in the $P$ into a local optimum. In case of binary encoding, we can switch a few randomly chosen bits from 1 to 0 or from 0 to 1 .

Another important concept in GA is the Elitism. The Elitism strategy (ES) was introduced by Kenneth De Jong in 1975 and is an addition to many selection methods that forces the GA to retain some number of the best individuals at each generation $(G)$. With this tool, such individuals can be lost if they are not selected to reproduce or if they are destroyed by $C$ or $M$. Many researchers have found that ES improves significantly the GA's performance [17-20].

The advantage of GA is in its parallelism. GA is travelling in a search space using more individuals than other methods. However, GA also has disadvantages, namely, the computational cost, because many times these algorithms are slower than other methodologies.

In this work we propose a fuzzy fractional $\mathrm{PD}^{\beta}+\mathrm{I}$ controller, where the gains will be tuned through the application of a GA, in order to achieve a superior control performance of the control system of Figure 1. The optimization fitness function corresponds to the minimization of the integral time absolute error (ITAE) criterion that measures the response error as defined as [20]

$$
J\left(K_{e}, K_{\mathrm{ce}}, K_{\mathrm{ie}}, K_{u}\right)=\int_{0}^{\infty} t|r(t)-c(t)| d t,
$$

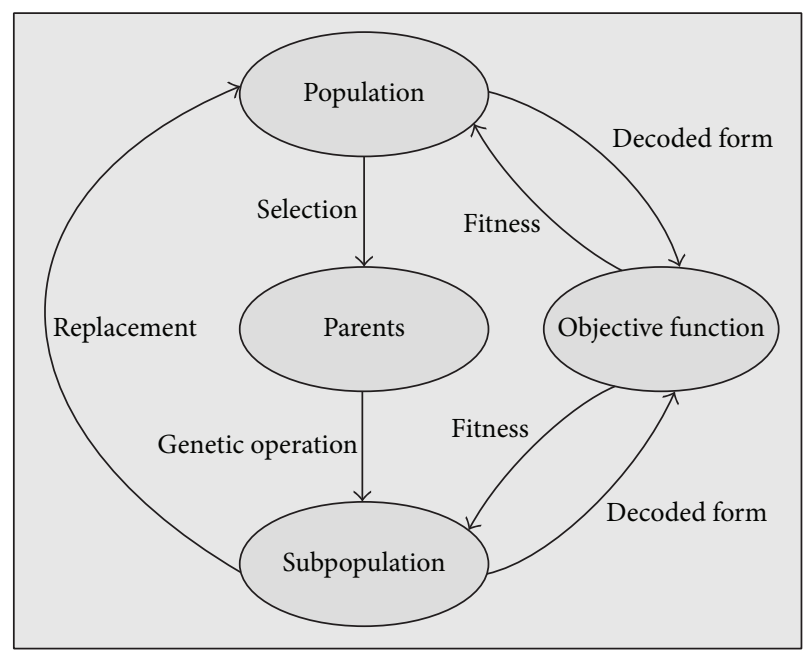

Figure 6: Block diagram of a GA.

where $\left(K_{e}, K_{\text {ce }}, K_{\mathrm{ie}}, K_{u}\right)$ are the $\mathrm{PD}^{\beta}+$ I controller parameters to be optimized.

During the minimization of the fitness function in GA, the chromosomes (potential solutions) that lead to unstable responses make the error take very high values penalizing the fitness function. Therefore, these chromosomes are less likely to be selected for reproduction or elitism, this way being destroyed or lost in the process. This mechanism ensures that only the best chromosomes are chosen to produce new population and that the GA converges to an optimal solution with a stable closed-loop system.

We can use other integral performance criteria such as the integral absolute error (IAE), the integral square error (ISE), or the integral time square error (ITSE). In the present study the ITAE criterion produced good results and is adopted in the sequel. Furthermore, the ITAE criterion enables us to study the influence of time in the error generated by the system.

\section{Simulation Results}

In this section we analyze the closed-loop system of Figure 1 with the fuzzy fractional $\mathrm{PD}^{\beta}+$ I controller of Figure 2 . The systems used correspond to typical plants [36, 37], namely, a high order process, a high order process with a zero, and a system with a time delay. In all the experiments, the fractional-order derivative $D^{\beta}$ is implemented using a 4 thorder Padé discrete rational transfer function $(m=n=4)$ of type (5). It is used as sampling period of $T_{c}=0.01 \mathrm{~s}$. The $\mathrm{PD}^{\beta}+\mathrm{I}$ controller is tuned through the optimization of fitness function corresponding to the minimization of ITAE (13) using a GA. We use $\delta=15$. We establish the following values for the GA parameters: population size $P=$ 20 , crossover probability $C=0.8$, mutation probability $M=0.05$, and number of generations $N_{G}=100$. The gene codification adopts a decimal code. It is important to refer that a reliable execution and analysis of a GA usually require a large number of simulations to guarantee that 
stochastic effects are properly considered [17, 19]. Therefore, the experiments consist in executing the GA several times, for generating a good combination of controller parameters. In this study the GA is repeated 10 times and we get the best result, that is, the simulation that leads to the smaller $J$. We set the search space of $K_{e}, K_{\mathrm{ce}}, K_{\mathrm{ie}}$, and $K_{u} \in[0,5]$.

In the first case, we compare a fuzzy fractional $\mathrm{PD}^{\beta}+\mathrm{I}$ controller $(\beta=0.9)$, with a fuzzy integer PD + I controller $(\beta=1)$. Figure 7 shows the unit step responses of both controllers. The plant system $G_{1}(s)$ used is represented by the transfer function:

$$
G_{1}(s)=\frac{1}{(s+1)(1+\alpha s)\left(1+\alpha^{2} s\right)\left(1+\alpha^{3} s\right)} \quad \text { with } \alpha=0.5 \text {. }
$$

The controller parameters, corresponding to the minimization of the ITAE index, lead to the values for the fuzzy integer PD + I controller: $\left\{K_{e}, K_{\mathrm{ce}}, K_{\mathrm{ie}}, K_{u}\right\} \equiv$ $\{1.0808,0.3408,0.3442,4.2095\}$, with $J=0.8235$, and for the fuzzy fractional $\mathrm{PD}^{\beta}+\mathrm{I}$ controller to the following values: $\left\{K_{e}, K_{\mathrm{ce}}, K_{\mathrm{ie}}, K_{u}\right\} \equiv\{0.7581,0.3510,0.3038,4.3276\}$, with $J=0.7693$. These values lead us to conclude that the fuzzy fractional-order controller produced similar results to integer one; however, the error $J$ is smaller, as can be seen in Figure 8, where it shows the ITAE error as function of $\beta$. The graph reveals that for this process we have a lower error for a fractional value of $\beta=0.9$. We verify that the fractional controller is better (in terms of error $J$ ) than the integer version, only in a narrow region of $0.8 \leq \beta<1$. Figure 9 illustrates the variation of FLC parameters $\left(K_{e}, K_{\mathrm{ce}}\right.$, $K_{\mathrm{ie}}, K_{u}$ ) as function of the order's derivative $\beta$, while Figure 10 shows the variation of the transient response parameters, namely, the settling time $t_{s}$, rise time $t_{r}$, peak time $t_{p}$, and overshoot $o v(\%)$ versus $\beta$, for the closed-loop step response. The variation of FLC parameters and the transient response parameters reveals a smooth variation with $\beta$.

In a second experiment, we consider a fuzzy $\mathrm{PD}^{\beta}+\mathrm{I}(\beta=$ $0.2)$ controller, for process $G_{2}(s)$ with a right-half plane zero, represented by the transfer function:

$$
G_{2}(s)=\frac{1-\alpha s}{(s+1)^{3}} \quad \text { with } \alpha=5.0 \text {. }
$$

Once again, we consider for comparison the corresponding integer version $(\beta=1)$. Figure 11 shows the unit step responses of both controllers.

The controller parameters, corresponding to the minimization of the ITAE index, lead to the values for the fuzzy integer controller: $\left\{K_{e}, K_{\mathrm{ce}}, K_{\mathrm{ie}}, K_{u}\right\} \equiv\{0.5393,0.4647$, $0.3439,0.2486\}$, with $J=75.4509$, and for the fuzzy fractional controller: $\left\{K_{e}, K_{\mathrm{ce}}, K_{\mathrm{ie}}, K_{u}\right\} \equiv\{0.6061,0.0326$, $0.3175,0.2909\}$, with $J=55.9414$. These values lead us to conclude that the fuzzy fractional-order controller produced better results than the integer ones, since the transient response (in particular the settling time and rise time) and the error $J$ are smaller. Figure 12 shows the ITAE error as function of $\beta$. The graph reveals that for this process we have a lower error for $\beta=0.2$. Also note that the fractional controller is better (in terms of error $J$ ) than the integer

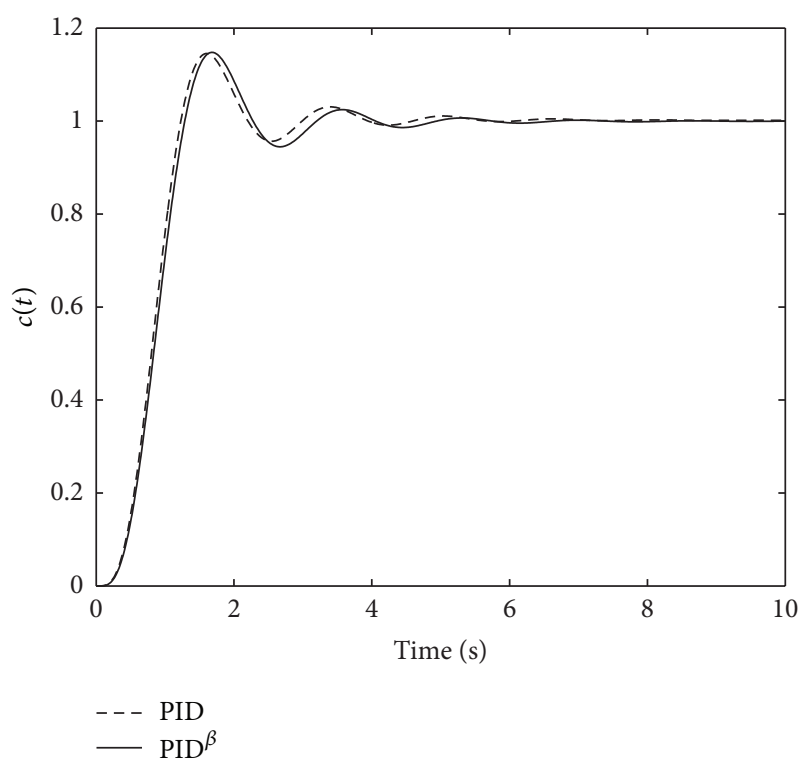

Figure 7: Step responses of closed-loop system with fuzzy PD + I and $\mathrm{PD}^{\beta}+\mathrm{I}(\beta=0.9)$ controllers.

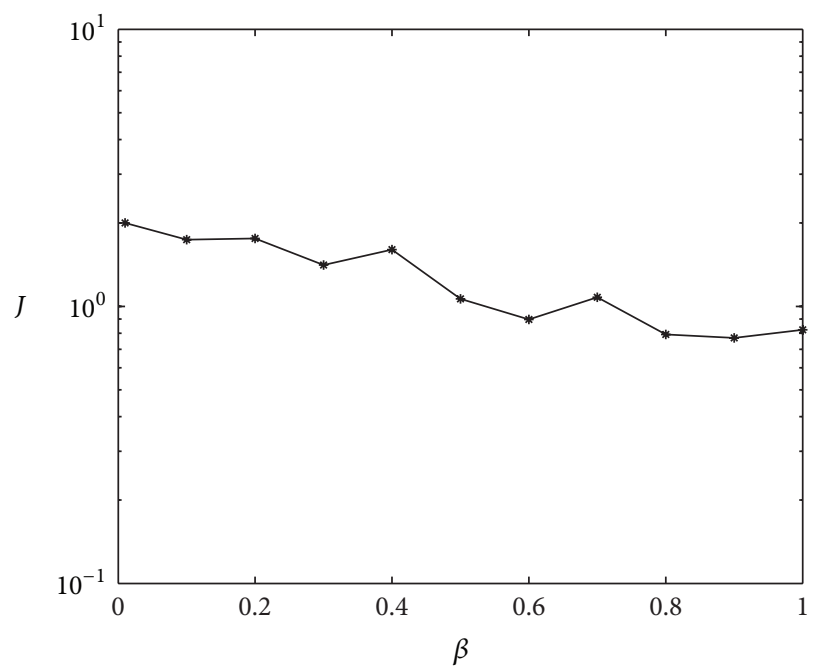

FIgURE 8: Error $J$ versus $\beta$ for $G_{1}(s)$.

one for $0.1 \leq \beta<1$. Figure 13 illustrates the variation of FLC parameters $\left(K_{e}, K_{\mathrm{ce}}, K_{\mathrm{ie}}, K_{u}\right)$ as function of the order's derivative $\beta$, while Figure 14 shows the variation of $t_{s}, t_{r}, t_{p}$ and $o v(\%)$ versus $\beta$, for the closed-loop step response. In this case, the $K_{\mathrm{ce}}$ and the $K_{\mathrm{ie}}$ have the smaller value near the best case (i.e., $\beta=0.2$ ) and $t_{s}, t_{r}$, and $t_{p}$ reveal similar values with the variation of $\beta$.

In a third study we consider a fuzzy $\mathrm{PD}^{\beta}+\mathrm{I}(\beta=$ $0.9)$ controller, for process $G_{3}(s)$, represented by the transfer function (16), where the time delay is $T=1[\mathrm{~s}]$ :

$$
G_{3}(s)=\frac{e^{-s T}}{(1+\alpha s)^{2}} \quad \text { with } \alpha=2.0 \text {. }
$$

For comparison purposes, we consider the corresponding integer version $(\beta=1)$. Figure 15 shows the unit step responses of both controllers. 

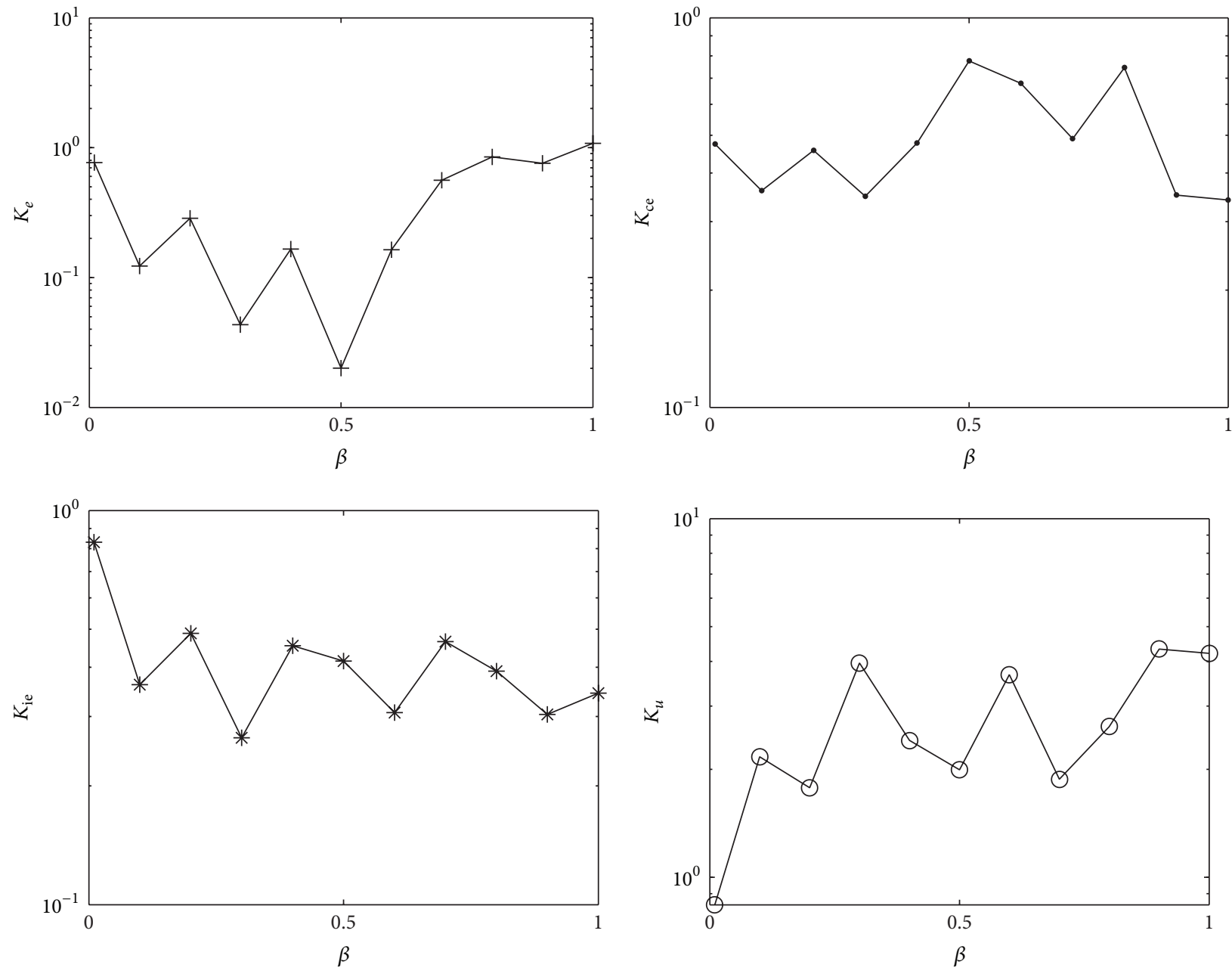

Figure 9: The $\operatorname{PID}^{\beta}$ parameters $\left(K_{e}, K_{\mathrm{ce}}, K_{\mathrm{ie}}, K_{u}\right)$ versus $\beta$ for $G_{1}(s)$.

The controller parameters, corresponding to the minimization of the ITAE index, lead to the values for the fuzzy integer controller: $\left\{K_{e}, K_{\mathrm{ce}}, K_{\mathrm{ie}}, K_{u}\right\} \equiv\{1.0496$, $0.9300,0.1757,2.2949\}$, with $J=7.2953$, and for the fuzzy fractional controller: $\left\{K_{e}, K_{\mathrm{ce}}, K_{\mathrm{ie}}, K_{u}\right\} \equiv\{0.6112$, $1.9142,0.1731,1.7278\}$, with $J=6.8251$. These values lead us again to remain the previous conclusions drawn for $G_{1}(s)$ and $G_{2}(s)$, namely, that the fuzzy fractional-order controller produced better results than the integer ones, since the transient response (viz., the overshoot and settling time) and the error $J$ are smaller. Figure 16 shows the ITAE error as function of $\beta$. The graph reveals that for this process we have a lower error for $\beta=0.9$. The fractional controller presents smaller values of $J$ for $0.8<\beta<1$. Figure 17 illustrates the variation of FLC parameters $\left(K_{e}, K_{\mathrm{ce}}, K_{\mathrm{ie}}, K_{u}\right)$ as function of the order's derivative $\beta$, while Figure 18 shows the variation of $t_{s}, t_{r}, t_{p}$, and $o v(\%)$ versus $\beta$ for the closed-loop step response. The FLC parameters reveal a slight variation with $\beta$, as well the transient response parameters.

In conclusion, with the fuzzy fractional $\mathrm{PD}^{\beta}+\mathrm{I}$ controller we get the best controller tuning, superior to the performance revealed by the integer-order scheme. Moreover, we prove the effectiveness of this control structure when used in systems with time delay. In fact, systems with time delay are more difficult to be controlled with the classical methodologies; however, the proposed algorithm reveals to be very effective in the control of this type of systems.

4.1. Fuzzy Fractional PID Structures. In this subsection we study the impact of different fuzzy fractional PID structures on system performance. For that, we compare the structure of Figure $2\left(S_{1}\right)$ used in the previous section with the structures of Figure $19\left(S_{2}\right)$ and Figure $20\left(S_{3}\right)$ applied to process $G_{3}(s)$. The GA was executed 10 times, and we get the result that leads to the smaller $J$. We consider the same fuzzy control rules base of Table 1 in all the structures $\left(S_{1}, S_{2}\right.$, and $\left.S_{3}\right)$.

The control action for these new structures is, respectively, for $\left(S_{2}\right)$ and $\left(S_{3}\right)$ :

$$
\begin{aligned}
U(k)=K_{u} v & +K_{\mathrm{ie}} I v=K_{u}[f(E, C E)]+K_{\mathrm{ie}} I[f(E, C E)] \\
=K_{u}[ & \left.f\left(K_{e} e(k), K_{\mathrm{ce}} D^{\beta} e(k)\right)\right] \\
& +K_{i e} I\left[f\left(K_{e} e(k), K_{\mathrm{ce}} D^{\beta} e(k)\right)\right]
\end{aligned}
$$



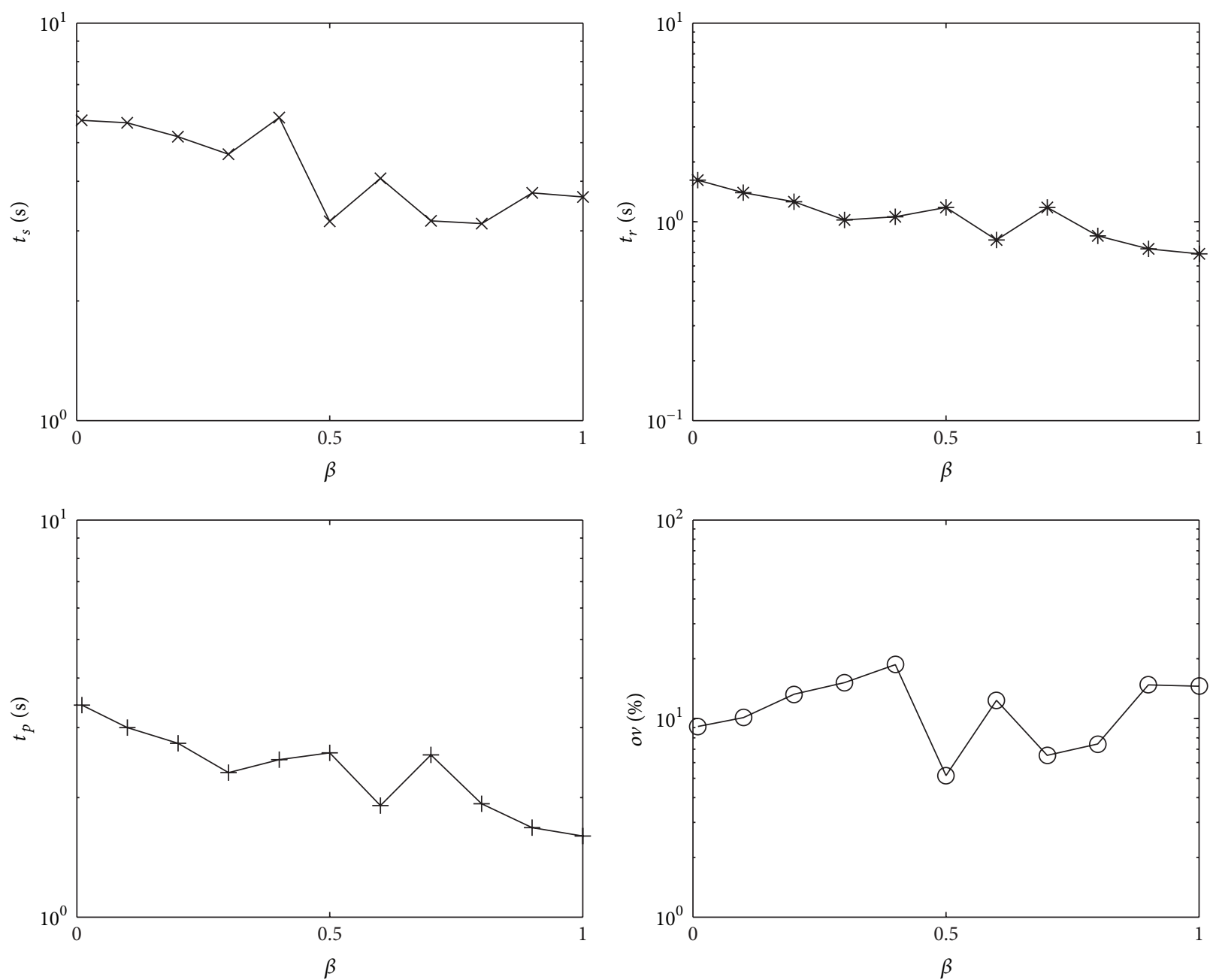

Figure 10: Parameters $t_{s}, t_{r}, t_{p}, o v(\%)$ versus $\beta$ of the step responses of the closed-loop system with $G_{1}(s)$ and with a fuzzy PD ${ }^{\beta}+I_{\text {controller. }}$

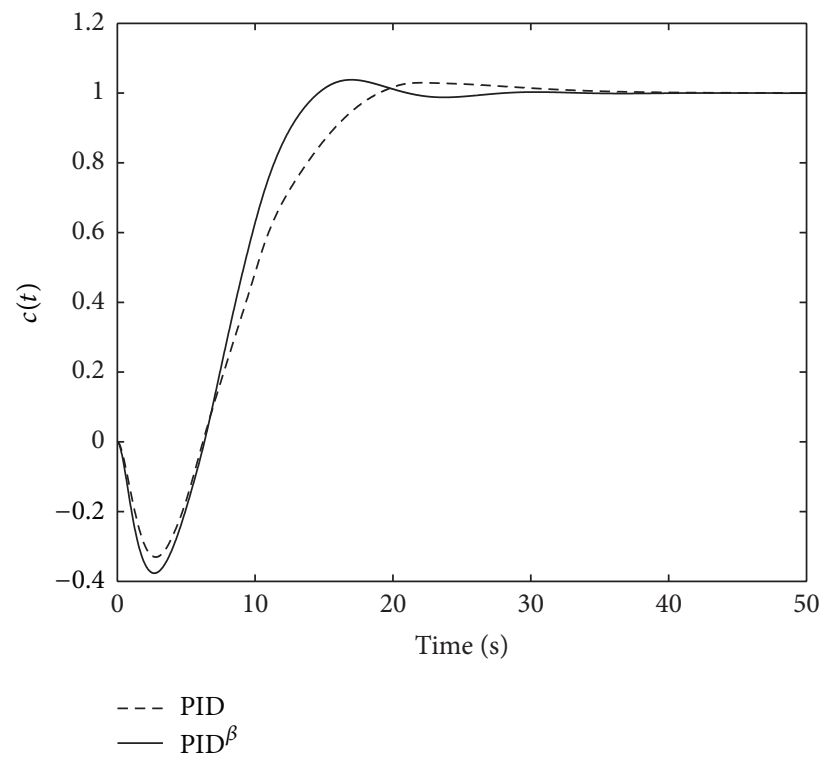

FIgURE 11: Step responses of closed-loop system with fuzzy PD $+\mathrm{I}$ and $\mathrm{PD}^{\beta}+\mathrm{I}(\beta=0.2)$ controllers. 


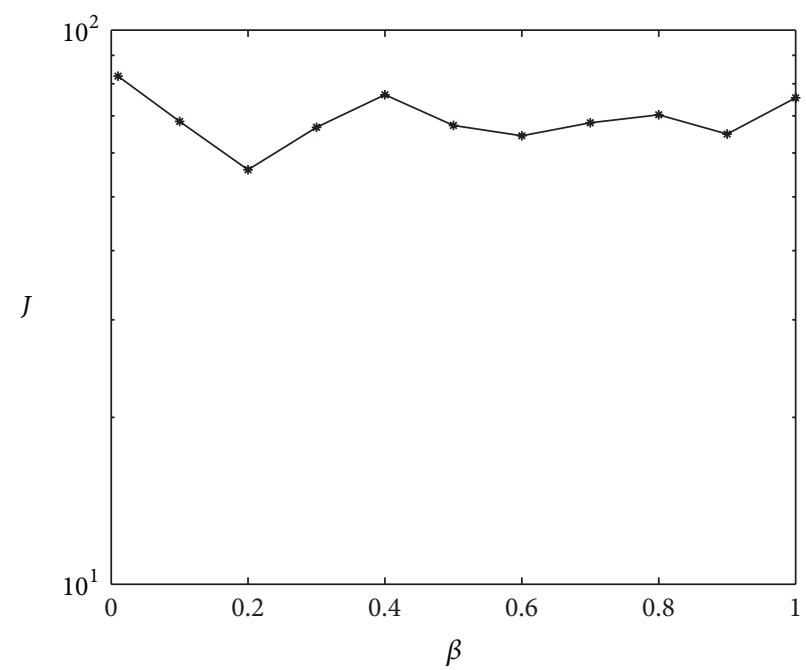

Figure 12: Error $J$ versus $\beta$ for $G_{2}(s)$.
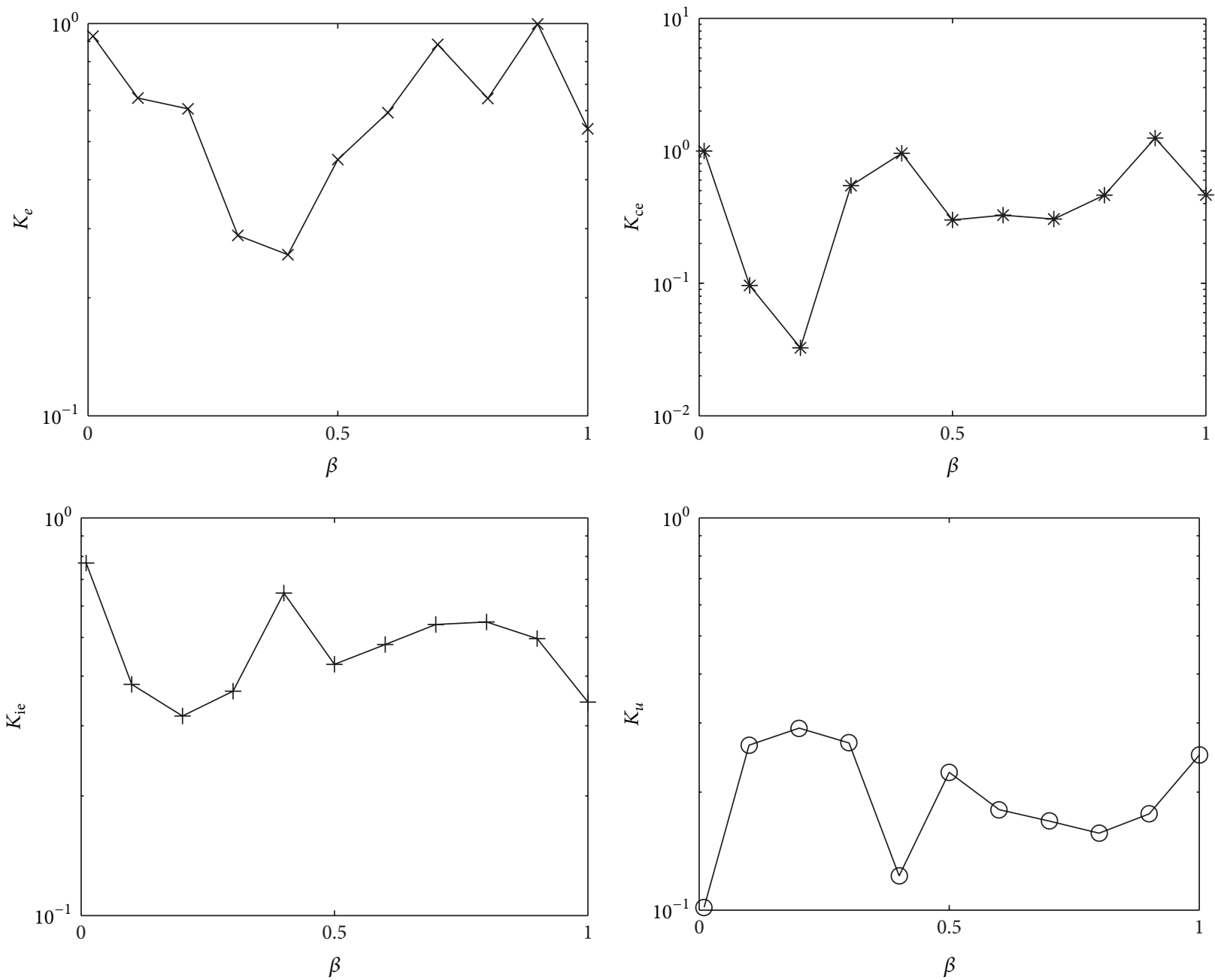

FIgURE 13: The $\mathrm{PD}^{\beta}+$ I parameters $\left(K_{e}, K_{\mathrm{ce}}, K_{\mathrm{ie}}, K_{u}\right)$ versus $\beta$ for $G_{2}(s)$. 

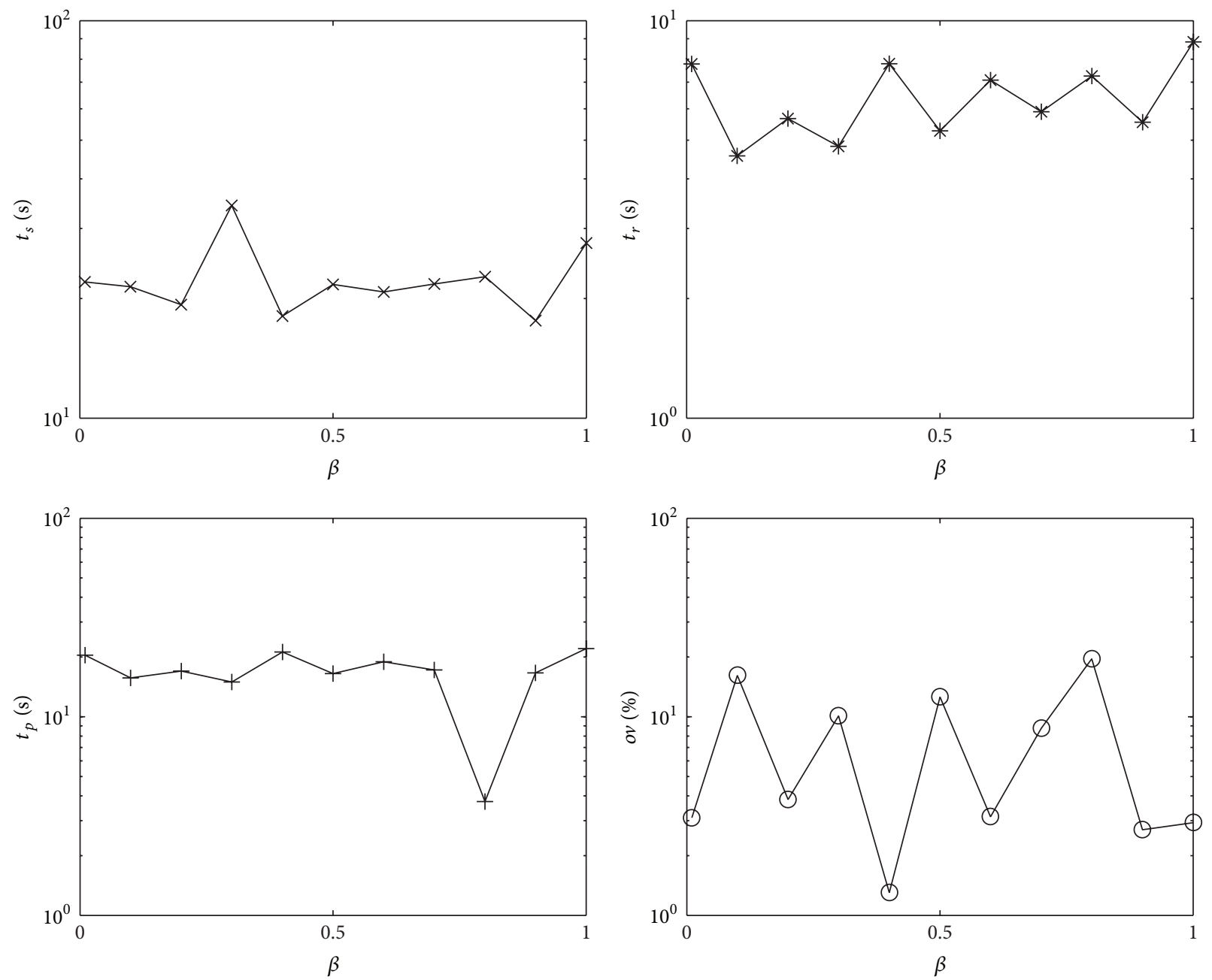

Figure 14: Parameters $t_{s}, t_{r}, t_{p}, o v(\%)$ versus $\beta$ of the step responses of the closed-loop system with $G_{2}(s)$ and with a fuzzy PD ${ }^{\beta}+\mathrm{I}(0<\beta \leq 1)$ controller.

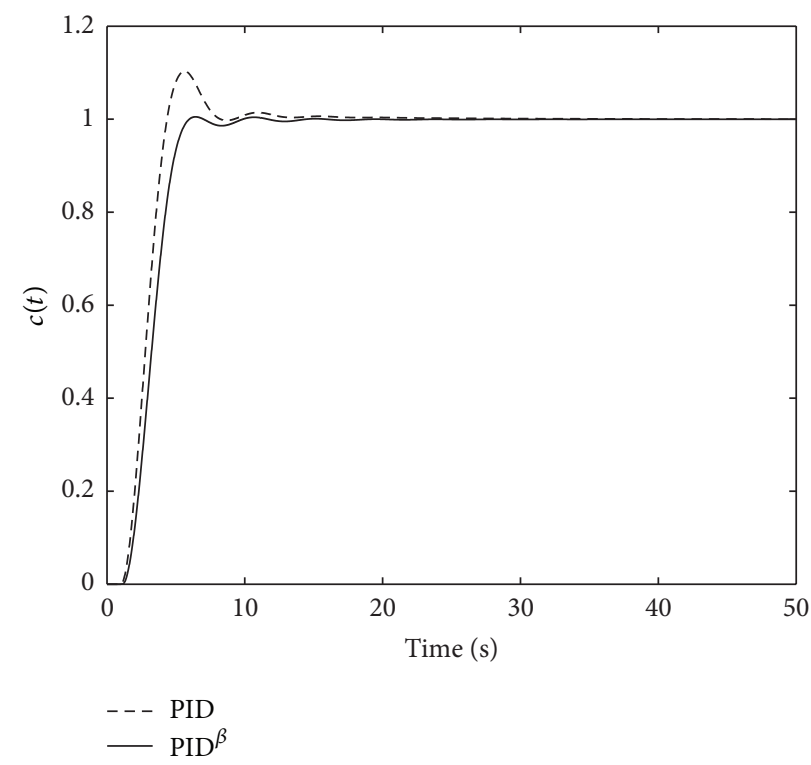

FIGURE 15: Step responses of closed-loop system with fuzzy PD $+\mathrm{I}$ and $\mathrm{PD}^{\beta}+\mathrm{I}(\beta=0.9)$ controllers. 


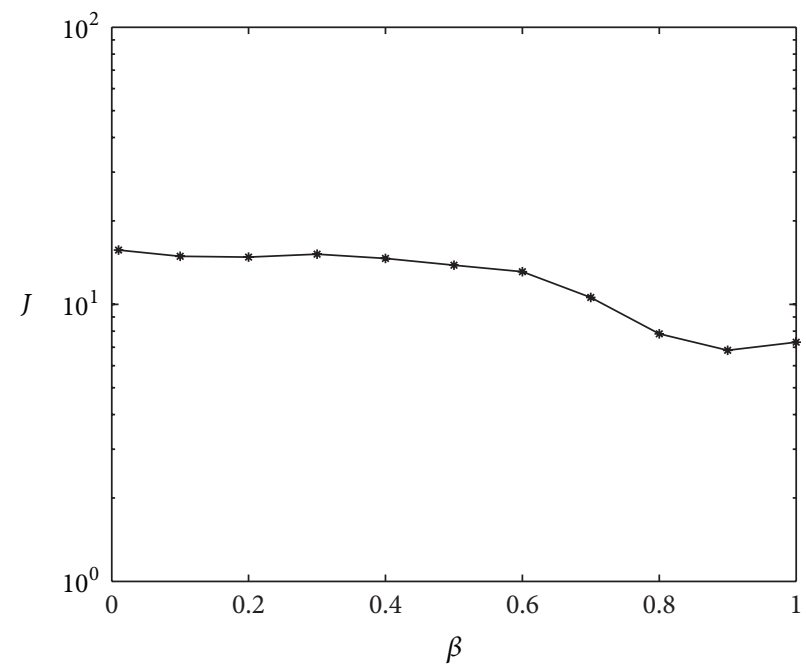

FigURE 16: Error $J$ versus $\beta$ for $G_{3}(s)$.
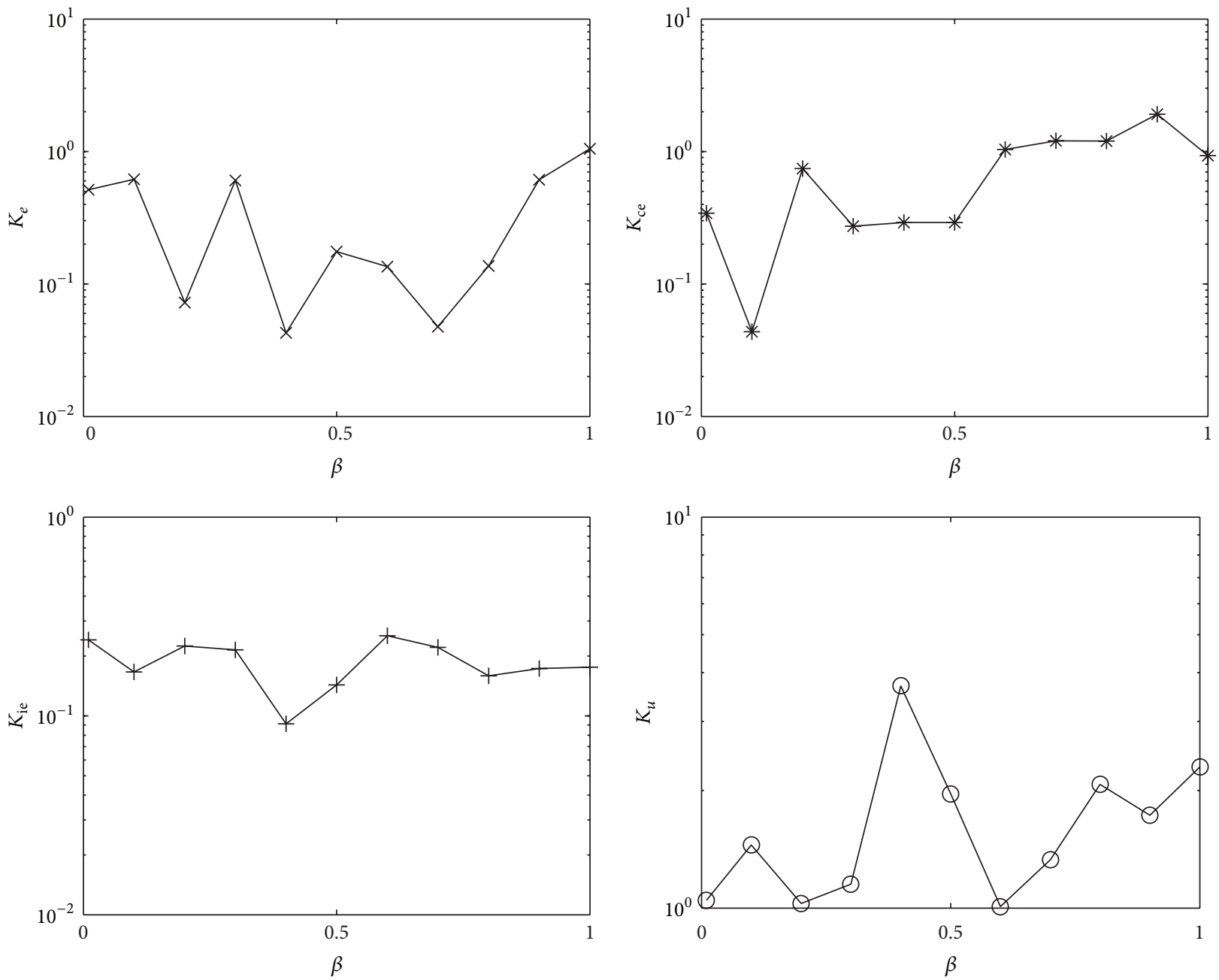

FIGURE 17: The $\mathrm{PD}^{\beta}+\mathrm{I}$ parameters $\left(K_{e}, K_{\mathrm{ce}}, K_{\mathrm{ie}}, K_{u}\right)$ versus $\beta$ for $G_{3}(s)$. 

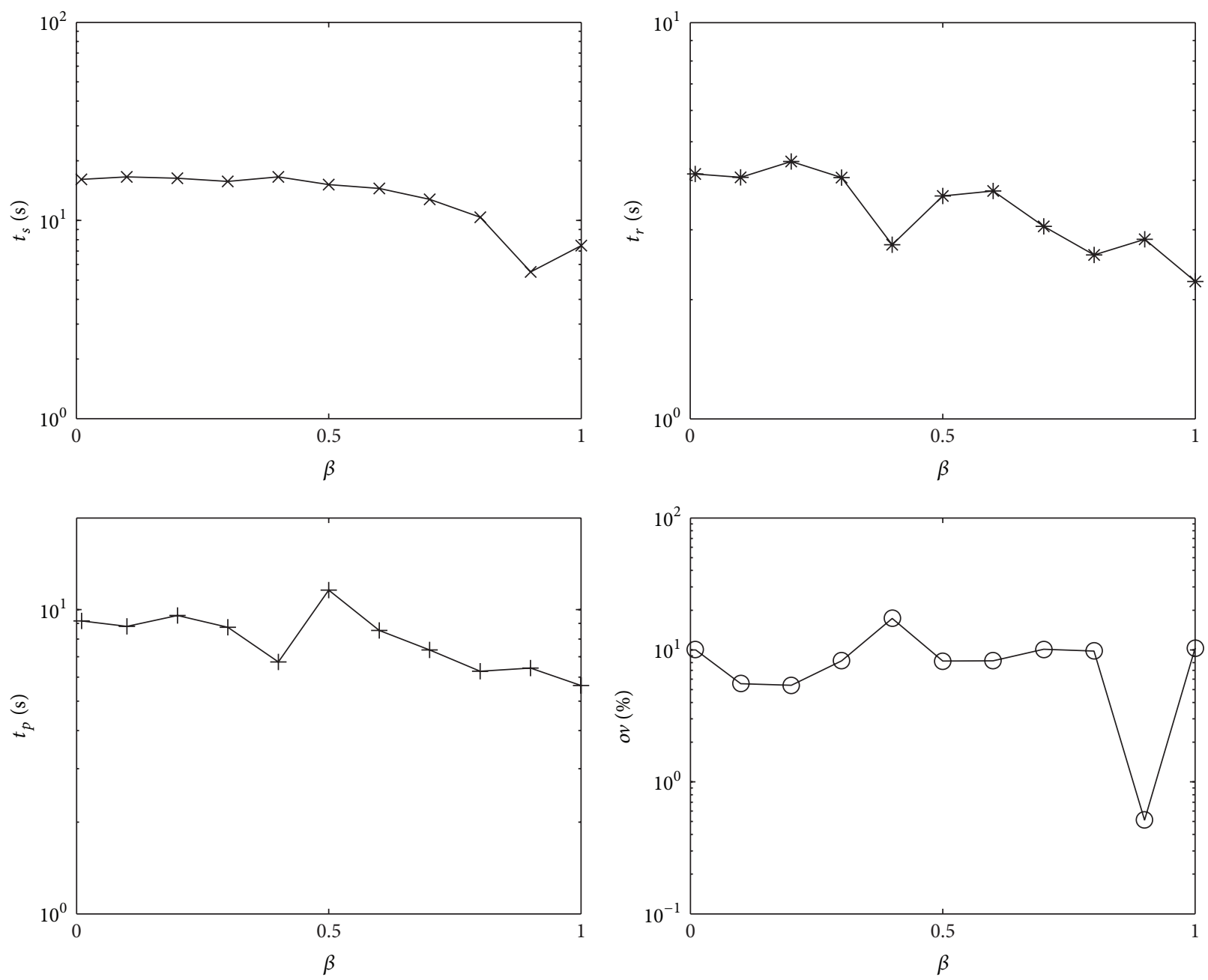

Figure 18: Parameters $t_{s}, t_{r}, t_{p}, o v(\%)$ versus $\beta$ of the step responses of the closed-loop system with $G_{3}(s)$ and with a fuzzy $\mathrm{PD}^{\beta}+\mathrm{I}(0<\beta \leq 1)$ controller.

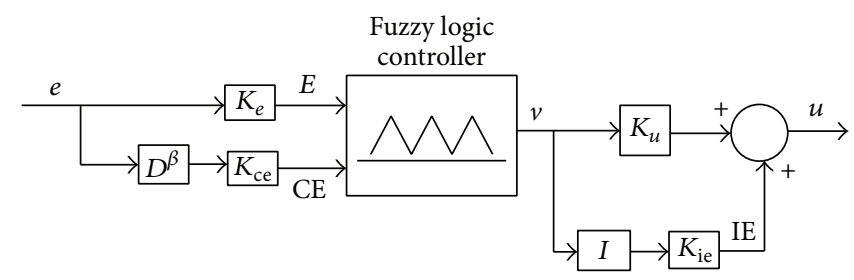

FiguRe 19: Fuzzy fractional PID controller $\left(S_{2}\right)$.

$$
U(k)=K_{\mathrm{PD}} v_{1}+K_{\mathrm{PI}} I v_{2},
$$

where

$$
\begin{aligned}
& v_{1}=f\left(E_{1}, \mathrm{CE}_{1}\right)=f\left(K_{e 1} e(k), K_{\mathrm{ce} 1} D^{\beta} e(k)\right), \\
& v_{2}=f\left(E_{2}, \mathrm{CE}_{2}\right)=f\left(K_{e 2} e(k), K_{\mathrm{ce} 2} D^{\beta} e(k)\right) .
\end{aligned}
$$

Figure 21 shows the unit step responses of fuzzy fractional controller for $S_{1}, S_{2}$, and $S_{3}$, for the best $J$. Figure 22 depicts the corresponding error as function of $\beta$. We verify that the lower error occurs for $\beta=0.9$ in $S_{1}, S_{2}$, and $S_{3}$, leading to errors $J=6.8251,5.8000$, and 6.2900, respectively.
Analyzing Figure 21 we observe that the step response is less oscillatory for $S_{1}$, with smaller values of $t_{r}$ and $t_{s}$ than other structures. Figure 22 shows that all three structures present similar results in terms of error $J$ as function of order $\beta$. Structures $S_{1}$ and $S_{2}$ give the most similar results while $S_{3}$ differs mostly on the regions around $\beta=0.1,0.5$, and 0.6 .

The different structures analyzed lead to similar results both in the step responses and error $J$. In fact, it is interesting to notice that the best $\beta=0.9$ for all the structures when minimizing the ITAE index. 


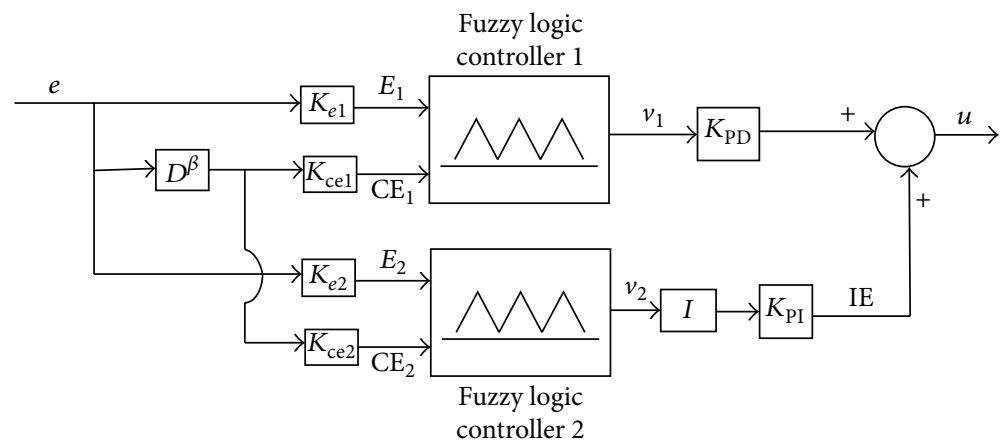

FIgURe 20: Fuzzy fractional PD + PI controller $\left(S_{3}\right)$.

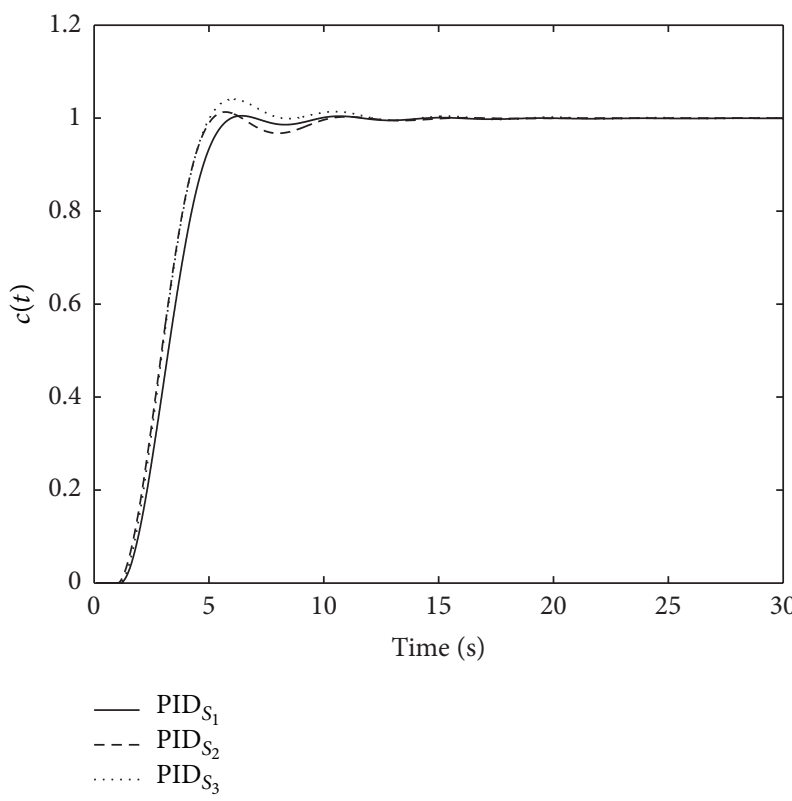

FIGURE 21: Step responses of closed-loop system with fuzzy fractional PID structures $S_{1}, S_{2}$, and $S_{3}$ for $G_{3}(s)$.

Based on this analysis we verify that the proposed $\mathrm{PD}^{\beta}+\mathrm{I}$ controller $\left(S_{1}\right)$ gives comparable and, in some situations, even better results than other two structures $\left(S_{2}\right.$ and $\left.S_{3}\right)$. Moreover, the adopted structure is simpler and easier to analyze and implement. These facts justify the choice of the structure $S_{1}$ used in this study.

\section{Conclusion}

This paper presented the fundamental aspects of application of the FC theory in fuzzy control systems. In this line of thought, several typical plants were studied. The dynamics of the closed-loop systems were analyzed in the perspective of $\mathrm{FC}$, with the use of a fuzzy $\mathrm{PD}^{\beta}+\mathrm{I}$ controller in which the parameters were tuned through a GA algorithm.

In general, the control strategies presented give better results than those obtained with conventional integer control structures, showing their effectiveness in the control of nonlinear systems.

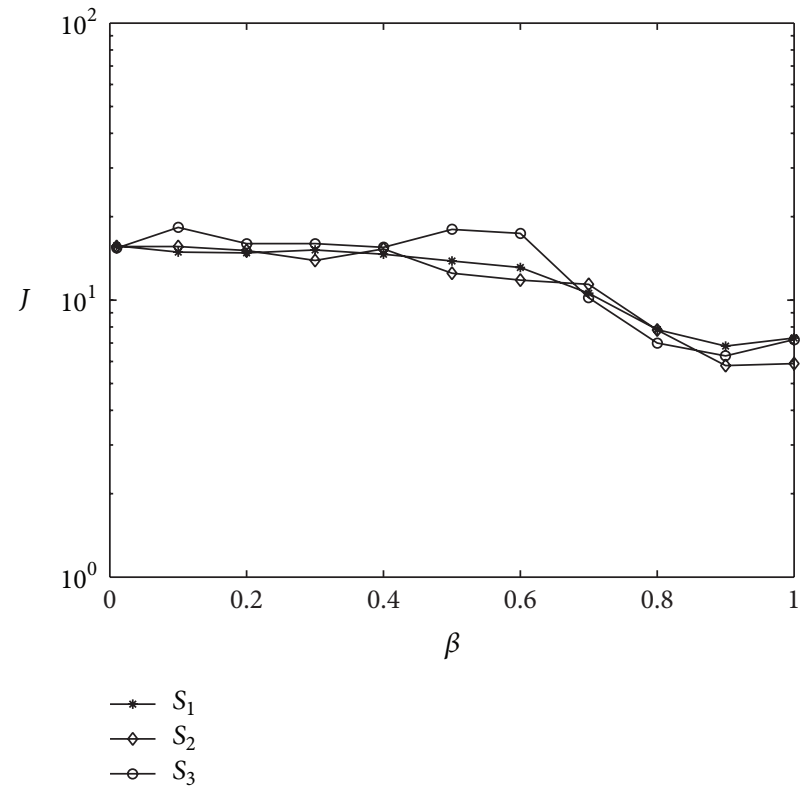

FIgURE 22: Error $J$ versus $\beta$ with the structures $S_{1}, S_{2}$, and $S_{3}$ for $G_{3}(s)$.

However, much research is still needed to understand their effective application in systems with larger time delays, and in the presence of noise and different actuator saturation levels.

\section{Conflict of Interests}

The authors declare that there is no conflict of interests regarding the publication of this paper.

\section{Acknowledgments}

This work is supported by FEDER Funds through the Programa Operacional Factores de CompetitividadeCOMPETE program and by National Funds through FCT Fundação para a Ciência e a Tecnologia. 


\section{References}

[1] K. B. Oldham and J. Spanier, The Fractional Calculus: Theory and Application of Differentiation and Integration to Arbitrary Order, Academic Press, New York, NY, USA, 1974.

[2] I. Podlubny, Fractional Differential Equations, vol. 198, Academic Press, San Diego, Calif, USA, 1999.

[3] R. Barbosa, "On linear fuzzy fractional PD and PD+I controllers," in Proceedings of the 4th IFAC Workshop Fractional Differentiation and Its Applications (FDA '10), Badajoz, Spain, 2010.

[4] R. Barbosa, I. Jesus, and M. Silva, "Fuzzy reasoning in fractional-order PD controllers," in Proceedings of the International Conference on New Aspects of Applied Informatics, Biomedical Electronics \& Informatics and Communications, Taipe, Taiwan, 2010.

[5] J. Carvajal, G. Chen, and H. Ogmen, "Fuzzy PID controller: design, performance evaluation, and stability analysis," Information Sciences, vol. 123, no. 3-4, pp. 249-270, 2000.

[6] S. Das, I. Pan, S. Das, and A. Gupta, "A novel fractional order fuzzy PID controller and its optimal time domain tuning based on integral performance indices," Engineering Applications of Artificial Intelligence, vol. 25, no. 2, pp. 430-442, 2012.

[7] S. Das, I. Pan, and S. Das, "Performance comparison of optimal fractional order hybrid fuzzy PID controllers for handling oscillatory fractional order processes with dead time," ISA Transactions, vol. 52, pp. 550-566, 2013.

[8] I. Eker and Y. Torun, "Fuzzy logic control to be conventional method," Energy Conversion and Management, vol. 47, no. 4, pp. 377-394, 2006.

[9] M. Mizumoto, "Realization of PID controls by fuzzy control methods," Fuzzy Sets and Systems in Information Science and Engineering, vol. 70, no. 2-3, pp. 171-182, 1995.

[10] H. Delavari, R. Ghaderi, A. Ranjbar, and S. Momani, "Fuzzy fractional order sliding mode controller for nonlinear systems," Communications in Nonlinear Science and Numerical Simulation, vol. 15, no. 4, pp. 963-978, 2010.

[11] G. K. I. Mann, B.-G. Hu, and R. G. Gosine, "Analysis of direct action fuzzy PID controller structures," IEEE Transactions on Systems, Man, and Cybernetics B: Cybernetics, vol. 29, no. 3, pp. 371-388, 1999.

[12] C. C. Lee, "Fuzzy logic in control systems: fuzzy logic controller. I, II," IEEE Transactions on Systems, Man, and Cybernetics, vol. 20, no. 2, pp. 404-435, 1990.

[13] K. M. Passino and S. Yurkovich, Fuzzy Control, Addison-Wesley, Longman, Boston, Mass, USA, 1997.

[14] M.-Y. Shieh and T.-H. S. Li, "Design and implementation of integrated fuzzy logic controller for a servomotor system," Mechatronics, vol. 8, no. 3, pp. 217-240, 1998.

[15] D. F. Jenkins and K. M. Passino, "An introduction to nonlinear analysis of fuzzy control systems," Journal of Intelligent \& Fuzzy Systems, vol. 7, no. 1, pp. 75-103, 1999.

[16] D. Maiti, A. Acharya, M. Chakraborty, A. Konar, and R. Janarthanan, "Tuning pid and $P I^{\lambda} D^{\mu}$ controllers using the integral time absolute error criterion," in Proceedings of the 4th International Conference on Information and Automation for Sustainability (ICIAFS '08), pp. 457-462, Colombo, Sri Lanka, December 2008.

[17] E. Goldberg, Genetic Algorithms in Search Optimization and Machine Learning, Addison-Wesley, 1989.

[18] M. Mitchell, An Introduction to Genetic Algorithms, SMIT Press, 1998.
[19] Z. Michalewicz, Genetic Algorithms + Data Structures = Evolution Programs, Springer, 1996.

[20] I. S. Jesus and J. A. T. Machado, "Implementation of fractionalorder electromagnetic potential through a genetic algorithm," Communications in Nonlinear Science and Numerical Simulation, vol. 14, no. 5, pp. 1838-1843, 2009.

[21] B. Hu, G. K. I. Mann, and R. G. Gosine, "New methodology for analytical and optimal design of fuzzy PID controllers," IEEE Transactions on Fuzzy Systems, vol. 7, no. 5, pp. 521-539, 1999.

[22] D. Rerkpreedapong, A. Hasanović, and A. Feliachi, "Robust load frequency control using genetic algorithms and linear matrix inequalities," IEEE Transactions on Power Systems, vol. 18, no. 2, pp. 855-861, 2003.

[23] F. Herrera and M. Lozano, Fuzzy Evolutionary Algorithms and Genetic Fuzzy Systems: A Positive Collaboration between Evolutionary Algorithms and Fuzzy Systems, Springer, Berlin, Germany, 2009.

[24] I. Jesus and J. Machado, "Application of fractional calculus in the control of heat systems," Journal of Advanced Computational Intelligence and Intelligent Informatics, vol. 11, no. 9, pp. 10861091, 2007.

[25] J. A. T. Machado, "Analysis and design of fractional-order digital control systems," Systems Analysis Modelling Simulation, vol. 27, no. 2-3, pp. 107-122, 1997.

[26] R. S. Barbosa, J. A. Tenreiro Machado, and M. F. Silva, "Time domain design of fractional differintegrators using leastsquares," Signal Processing, vol. 86, no. 10, pp. 2567-2581, 2006.

[27] P. Ivo and B. M. Vinagre, "Practical application of digital fractional-order controller to temperature control," Acta Montanistica Slovaca, vol. 7, no. 2, pp. 131-137, 2002.

[28] I. Podlubny, "Fractional-order systems and $P I^{\lambda} D^{\mu}$-controllers," IEEE Transactions on Automatic Control, vol. 44, no. 1, pp. 208214, 1999.

[29] Y. Chen, B. M. Vinagre, and I. Podlubny, "Continued fraction expansion approaches to discretizing fractional order derivatives-an expository review," Nonlinear Dynamics, vol. 38, no. 1-4, pp. 155-170, 2004.

[30] B. M. Vinagre, Y. Q. Chen, and I. Petráš, “Two direct Tustin discretization methods for fractional-order differentiator/integrator," Journal of the Franklin Institute, vol. 340, no. 5, pp. 349-362, 2003.

[31] S. Jesus, J. Machado, and S. Barbosa, "Fractional order nonlinear control of heat system," in Proceedings of the 13rd Workshop on Fractional Differentiation and Its Applications (IFAC-FDA '08), Ankara, Turkey, 2008.

[32] I. S. Jesus and J. A. Tenreiro Machado, "Fractional control of heat diffusion systems," Nonlinear Dynamics, vol. 54, no. 3, pp. 263-282, 2008.

[33] Y. Chen, "Ubiquitous fractional order controls?" in Proceedings of the 2nd IFAC Symposium on Fractional Derivatives and Applications (IFAC-FDA '06), p. 12, Porto, Portugal, July 2006.

[34] J. Jantzen, Foundations of Fuzzy Controllers, John Wiley \& Sons, 2007.

[35] K. Passino and S. Yurkovich, Fuzzy Control, Addison-Wesley, 1998.

[36] K. H. Ang, G. Chong, and Y. Li, "PID control system analysis, design, and technology," IEEE Transactions on Control Systems Technology, vol. 13, no. 4, pp. 559-576, 2005.

[37] K. J. Åström and T. Hägglund, PID Controllers: Theory Design and Tuning, ISA Press, Research Triangle Park, 1995. 


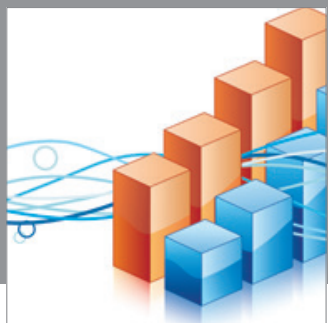

Advances in

Operations Research

mansans

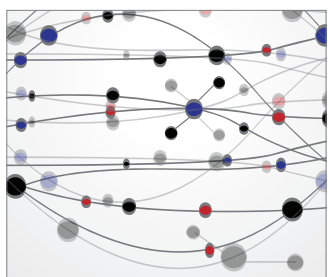

The Scientific World Journal
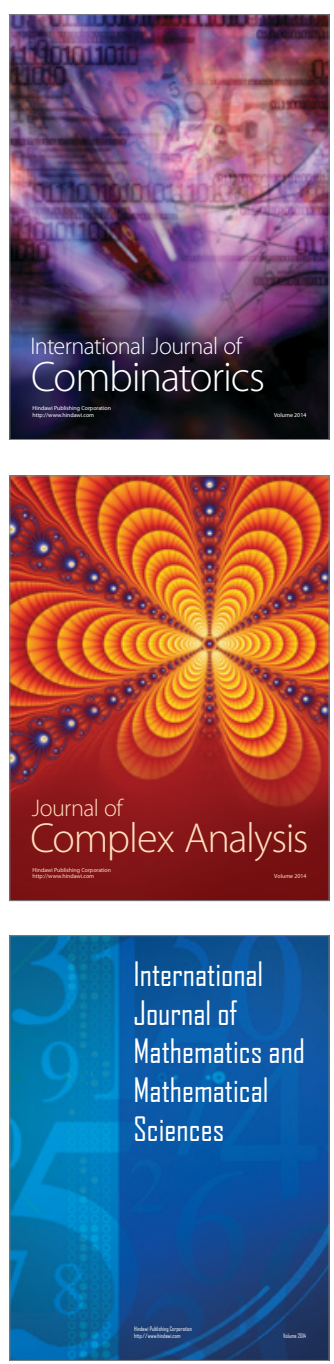
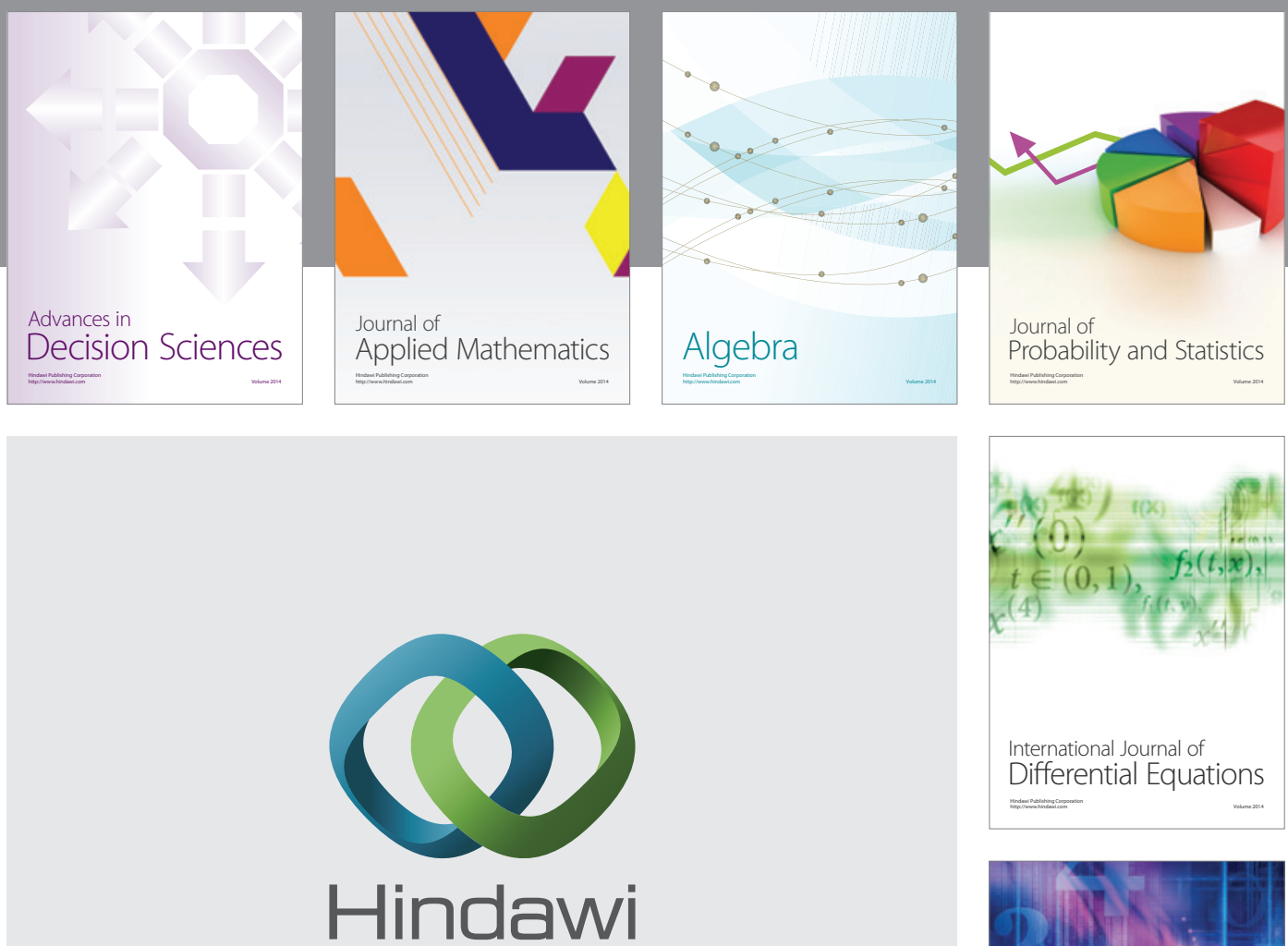

Submit your manuscripts at http://www.hindawi.com
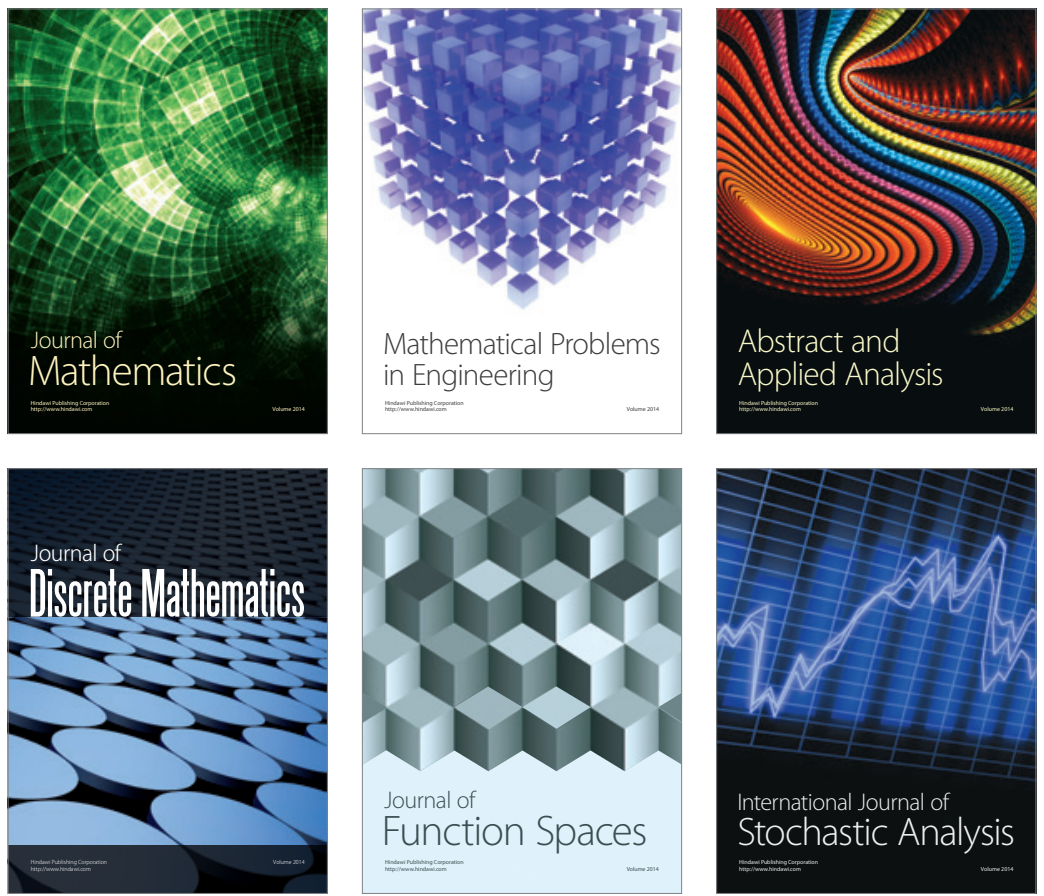

Journal of

Function Spaces

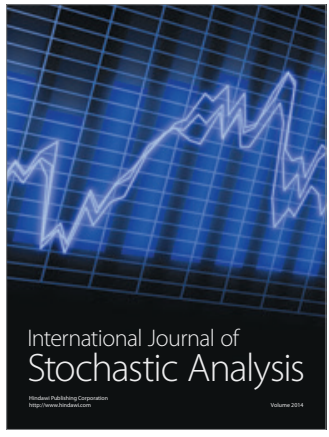

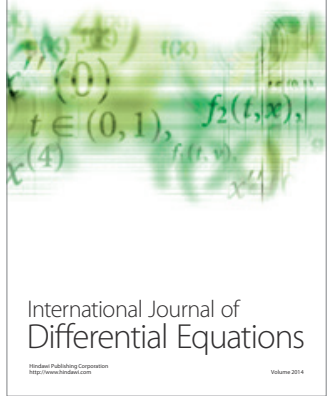
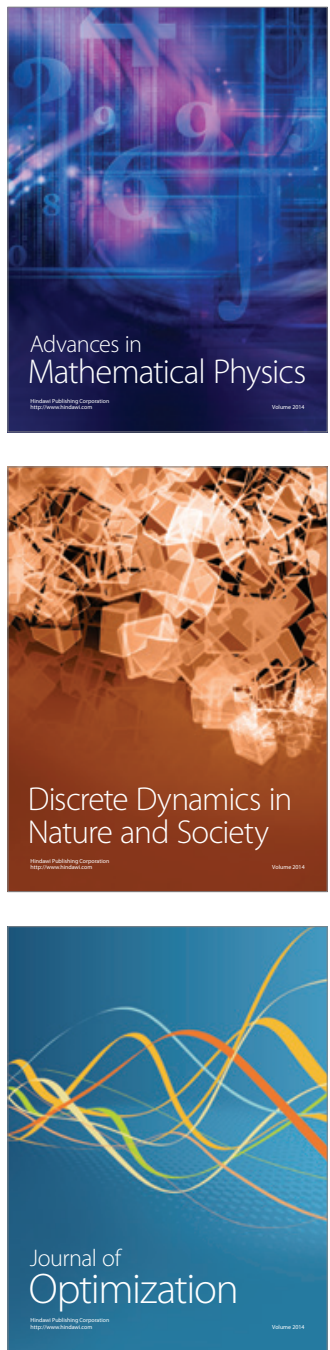